\title{
16. インポータンス方程式の物理的意味
}

\author{
大塚益比 古*
}

\section{Physical Meaning of the Importance Equation}

By M.OTSUKA

Since the importance function has the clear meaning in the reactor theory, the importance equation should also have a certain physical meaning. In the present paper the importance equation and its boundary condition in the diffusion approximation are examined, and it is shown that the equation and the boundary condition are based on the same physical approximation as the original reactor equation, to which the importance equation is adjoint.

\section{まえがき}

インポータンス (Importance) の従 5 万程式は数学 的には原子炉方程式の随伴方程式であり，インポータ ンスは随伴函数である。物理的にはそれは定常状態に ある原子炉中のある場所におかれた中性子が自分自身 とその子係のすべてによって連鎖反応に寄与する程度 （相刘的価値）を示寸量である。してみればインポー タンス方程式すまた明瞭な物理的意味をもっているべ きである。Boltzmann 方程式型（渝送方程式）の随伴 方程式に対してはすてに明快な論交 ${ }^{(1)}$ があるか，ここ では拡散型のものについて考察した。また境界条件に 対してる考察を行なった。

\section{I . インポータンス方程式の誘導}

原子师方程式として扗散型のるのをとり，定常状態 で

$$
\begin{aligned}
& D \Delta \phi(\boldsymbol{x})-\Sigma_{a}(\boldsymbol{x}) \phi(\boldsymbol{x}) \\
& \quad+\iiint K\left(\boldsymbol{x}, \boldsymbol{x}^{\prime}\right) k \Sigma_{a}\left(\boldsymbol{x}^{\prime}\right) \phi\left(\boldsymbol{x}^{\prime}\right) d x^{\prime}=0
\end{aligned}
$$

とする。ただ $\phi(\boldsymbol{x})$ は熱中性子束, $K\left(\boldsymbol{x}, \boldsymbol{x}^{\prime}\right)$ は減 速積分核であり，Dは空間的に一定としている。

$t=0$ で点 $x_{0}$ にあった1個の熱中性子に注目する とその空間移動を支配する方程式は，したがって

$$
\begin{gathered}
D_{0} \Delta n(\boldsymbol{x}, t)=\frac{\partial n(\boldsymbol{x}, t)}{\partial t} \\
D_{0}=D v \\
n(\boldsymbol{x}, 0)=\delta\left(\boldsymbol{x}-\boldsymbol{x}_{0}\right)
\end{gathered}
$$

である。吸収の過程は無視した。
この解はただちにえられて

$$
n(x, t)=\frac{1}{\left(4 \pi D_{0} t\right)^{3 / 2}} e^{-\left|x-x_{0}\right|^{2} / 4 D_{0} t}
$$

となり，存在確率は点 $\boldsymbol{x}_{0}$ を中心にした Gauss 分布を とる。 $t=0$ において $\phi^{*}\left(x_{0}\right)$ なるインポータンスを むっていた中性子は，この空間移動によって，時刻 $t$ においてもつインポータンスは

$$
\iiint \phi^{*}(\boldsymbol{x}) n(\boldsymbol{x}, t) d \boldsymbol{x}
$$

となる。 $t$ が十分小さく $t=\delta t$ とおけば, $n(x, \delta t)$ は $\boldsymbol{x}_{0}$ の近くでしか值をるたないから， $\boldsymbol{\phi}^{*}(\boldsymbol{x})$ を点 $\boldsymbol{x}_{0}$ で Taylor 展開し, 展開の第 3 項まてにとどめれば,

$$
\begin{aligned}
& \iiint \phi^{*}(\boldsymbol{x}) n(\boldsymbol{x}, \delta t) d \boldsymbol{x} \\
& \quad=\iiint\left[\phi^{*}\left(\boldsymbol{x}_{0}\right)+\sum_{t}\left(x_{i}-x_{0 t}\right) \frac{\partial \phi^{*}\left(\boldsymbol{x}_{0}\right)}{\partial x_{i}}\right. \\
& \left.\quad+\frac{1}{2} \sum_{i} \sum_{j}\left(x_{i}-x_{0 t}\right)\left(x_{j}-x_{0 j}\right) \frac{\partial^{2} \phi^{*}\left(\boldsymbol{x}_{n}\right)}{\partial x_{i} \partial x_{j t}}+\cdots\right] \\
& =\frac{1}{\left(4 \pi D_{0} \delta t\right)^{3 / 2}} e^{-\mid x-x_{0} i^{2}+D_{0} \delta t} d \boldsymbol{x} \\
& =\phi^{*}\left(\boldsymbol{x}_{0}\right)+D_{0} \delta t \cdot \Delta \phi^{*}\left(\boldsymbol{x}_{0}\right)+\cdots
\end{aligned}
$$

となる。省略した項は $\delta t$ に関して 2 次以上である。

さて同じ $\delta t$ 時間中の吸収について考えると， $v \delta t / \lambda_{a}\left(x_{0}\right)=\Sigma_{a}\left(x_{0}\right) v \delta t$ の確率で中性子が消失して いるから，そのために

$$
-\phi^{*}\left(x_{0}\right) \Sigma_{a}\left(x_{0}\right) v \delta t
$$

だけのインポータンスの減少がある。けれどす核分裂

* 電源開発株式会社 (Electric Power Development Co.) 
によって同じ $\delta t$ 中に $k \Sigma_{a}\left(\boldsymbol{x}_{0}\right) v \delta t$ 個の分裂中性子か; 生み出され，中かて $K\left(\boldsymbol{x}, \boldsymbol{x}_{0}\right)$ の確率で点 $\boldsymbol{x}$ において 熱中性子となり，その熱中性子は $\phi^{*}(\boldsymbol{x})$ なるインポ ータンスをわつ。したかっってこのインポータンスの総 量は

$$
k \Sigma_{\boldsymbol{a}}\left(\boldsymbol{x}_{0}\right) v \delta t \iiint \phi^{*}(\boldsymbol{x}) K\left(\boldsymbol{x}, \boldsymbol{x}_{0}\right) d \boldsymbol{x}
$$

となる。

まえがきに述べたインポータンスのるつ物理的内容 から考えて,この量は時間的に保存しなければならな い。すなわち $t=0$ においてっっていた值と， $t=$ $\delta t$ に扣ける值すなわち(7)，(8)，(9) 式の和は等 しくなけ札ばならない。

$$
\begin{aligned}
\phi^{*}\left(\boldsymbol{x}_{0}\right)= & \phi^{*}\left(\boldsymbol{x}_{0}\right)+D_{0} \delta t \cdot \Delta \phi^{*}\left(\boldsymbol{x}_{0}\right) \\
& -\Sigma_{a}\left(\boldsymbol{x}_{0}\right) v \delta t \phi^{*}\left(\boldsymbol{x}_{0}\right) \\
& +k \Sigma_{a}\left(\boldsymbol{x}_{0}\right) v \delta t \iiint K\left(\boldsymbol{x}, \boldsymbol{x}_{0}\right) \phi^{*}(\boldsymbol{x}) d \boldsymbol{x}
\end{aligned}
$$

この方程式から共通の項を消去し，両辺を $v \delta t て ゙$ 割

$\eta, x_{0}$ を $\boldsymbol{x}$ とあらためれば

$$
\begin{aligned}
& D \Delta \phi^{*}(\boldsymbol{x})-\Sigma_{a}(\boldsymbol{x}) \phi^{*}(\boldsymbol{x}) \\
& \quad+k \Sigma_{a}(\boldsymbol{x}) \iiint K\left(\boldsymbol{x}^{\prime}, \boldsymbol{x}\right) \phi^{*}\left(\boldsymbol{x}^{\prime}\right) d \boldsymbol{x}^{\prime}=0
\end{aligned}
$$

となる。これは(1)式の随伴方程式にほかならない。 こ5してインポータンス方程式はインポータンスの保 存則にほかならないことが示された。

多数組近似の場合も同様にインポータンス保存則を 意味している。二組近似を例にとれば，随伴方程式は

$$
\begin{aligned}
& D_{1} \Delta \phi_{1}{ }^{*}-\Sigma_{1} \phi_{1}{ }^{*}+\Sigma_{1} \phi_{2}{ }^{*}=0 \\
& D_{2} \Delta \phi_{2}{ }^{*}-\Sigma_{2} \phi_{2}{ }^{*}+k \Sigma_{2} \phi_{1}{ }^{*}=0
\end{aligned}
$$

である。添え字 1 は速い中性子の組，2は熱中性子の 組を示す。（1）式に $v_{1} \delta t$ を乗ずれば，第 1 項は $\delta t$ 間 の空間移動によって生ずるインボータンスの変化量の である。同じ $\delta t$ 中に減速によって $\Sigma_{1} v_{1} \delta t$ の割合いで 速い中性子は消失するが，方の結果は $\phi_{2}{ }^{*}$ なるインポ 一タンスをもつ熱中性子の誕生になるからこの間の 正味の変化は $\Sigma_{1} v_{1} \delta t\left(\phi_{2}{ }^{*}-\phi_{1}{ }^{*}\right)$ となる。これが第 2 項と第 3 項に相当する。(12)式の第 2 式についても同 棣に解秎される。

\section{II. 境界条件の誘望}

Boltzmann 型のインポータンス方程式の場合の境界 条件はほとんど自明であるが，抬散型の方程式の場合
はそ5ではない。るちろん数学的には随伴函数のるつ べき性質からただちに境界条件がえられる。すなわち 中性子束に対する境界条件か，自由表面で（外插表面 上で） $\phi=0,2$ 媒質間の境界で $\phi$ と $D \partial / \partial \nu か ゙$ 連

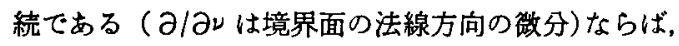
随伴函数 $\phi^{*}$ に対しても

$$
\begin{aligned}
& \text { 自由表面（外㨂表面）て } \phi^{*}=0 \\
& 2 \text { 媒質間の境界で }
\end{aligned}\left\{\begin{array}{l}
\phi^{*} \text { 連続 } \\
D \frac{\partial \phi^{*}}{\partial \nu} \text { 連続 }
\end{array}\right.
$$

となるべきことはたやすく示すことができる。ここで はこれらの条件を物理的に尊きたい。

すっとあ簡単な条件からふれることにする。

\section{1. 自由表面, $\phi^{*}=0$}

中性子束を外捙表面で 0 とする手続きはよく知られ ているように物理的手続ではない。そのためインポー タンスに対しても $\phi^{*}=0$ を物理的手続から求めるこ とはできない。しいていえば,(外㧴) 表面上におかれ た中性子はある抽象的手続によって必ず消されるので あるから，したがってインポータンスは0であるとい うことになる。

\section{2 媒所の境界面て $\phi^{*}$ が連䊺}

境界をはさんで十分近い2点を考え，その距離を無 限に接近させれば，その 2 点におかれた中性子は全く 同等になる。したがってインポータンスもまた同等で なければならない。

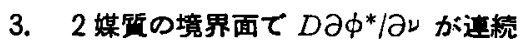

境界が平面であるとし， $t=0$ において境界面上に 単位面積当り1個のわりで中性子が存在したとする。 その後の挙動は (2)，（3）（4)式を一次元化した方 程式で与えられ，解はすぐにえられる。すなわち

$$
\begin{aligned}
& n(x, t)=\frac{A}{\left(4 \pi D_{\mathrm{A}} t\right)^{1 / 2}} e^{-x^{2} / 4 D_{\mathrm{A}} t}(x<0) \\
& \quad+\frac{B}{\left(4 \pi D_{\mathrm{B}} t\right)^{1 / 2}} e^{-x^{2} / 4 D_{\mathrm{B}^{t}}}(x>0) \\
& \left.\begin{array}{l}
A=2 /\left(1+\left(D_{\mathrm{B}} / D_{\mathrm{A}}\right)^{1 / 2}\right) \\
B=2 /\left(1+\left(D_{A} / D_{\mathrm{B}}\right)^{1 / 2}\right) \\
A / B=\left(D_{\mathrm{A}} / D_{\mathrm{B}}\right)^{1 / 2}
\end{array}\right\}
\end{aligned}
$$

となる。ただし，境界面を原点にとり垂直に $x$ 軸をと って, $x<0$ を媒質, $x>0$ をB媒質とした。 $D_{A}$ と $D_{\mathbf{B}}$ は各媒質のるつ $D_{0}((3)$ 式)である。定数 $A$ 打 よびBは， $x=0$ における $n(0, t)$ の連続性と, 規 格化条件 $\int n(x, t) d x=1$ からきまる。

$t=0$ Kおいて $\phi^{*}(0)$ なるインポータンスをすっ

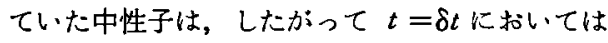




$$
\int \phi^{*}(x) n(x, \delta t) d x
$$

をもつこととなり,インポータンスの保存則により両 者は相等しい。(14)式を用い，前節と同様に $\delta t$ が小 さいとして， $\phi^{*}(x)$ を Taylar 展開して高次の項を 無視すれば

$$
\begin{gathered}
\phi^{*}(0)=\int_{-\infty}^{0}\left[\phi^{*}(0-)+x \frac{d \phi^{*}(0-)}{d x}+\cdots\right] \\
\cdot \frac{A}{\left(4 \pi D_{\mathrm{A}} \delta t\right)^{1 / 2}} e^{-x^{2} / 4 D_{\mathrm{A}} \delta^{t}} d x \\
+\int_{0}^{\infty}\left[\phi^{*}(0+)+x \frac{d \phi^{*}(0+)}{d x}+\cdots\right] \\
\cdot \frac{B}{\left(4 \pi D_{\mathrm{B}} \delta t\right)^{1 / 2}-e^{-x^{2} / 4 D_{\mathrm{B}} \delta t} d x} \\
=\frac{A}{2} \phi^{*}(0-)-\frac{A}{2}\left(\frac{4 D_{\mathrm{A}} \delta t}{\pi}\right)^{1 / 2} \frac{d \phi^{*}(0-)}{d x}+\cdots \\
+\frac{B}{2} \phi^{*}(0+)+\frac{B}{2}\left(\frac{4 D_{\mathrm{B} \delta} \delta}{\pi}\right)^{1 / 2} \frac{d \phi^{*}(0+)}{d x}+\cdots
\end{gathered}
$$

となる。前項に述べた $\phi^{*}(0-)=\phi^{*}(0+)=\phi^{*}(0)$ と いう境界条件を用い，(15)式で与えた $A ， B$ の関係式 を用いれば

$$
D_{\mathbf{A}} \frac{d \phi^{*}(0-)}{\underset{\mathbf{C}}{d x}}=D_{\mathrm{B}} \frac{d \phi^{*}(0+)}{d x}
$$

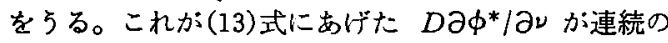
条件にほかならない。

\section{【.むすび}

中性子が自由表面の近くや，2 媒質の境界，中性子 源の近くでは Fick の法則に従う拡散を行なわないこ とはすでに詳しく解析されているので(2)，その意味で は（5)式や(14)式の中性子密度分布は正確なるのでは ない。けれども拡散型の原子祅方程式を採用した以上 は，中性子束はいたるところで Fick の法則に従う执 散を行ならと仮定したことになる。その結果として， インポータンスの保存則から自働的にインポータンス 方程式と境界条件を導くことができることを示したの であって，いいかえれば，中性子束の方程式とインポ 一タンス方程式およびその境界条件が物理的に同じ近 似の上に立っていることを明らかにしたといえる。

\section{（1959年 6月 29 日 受理）}

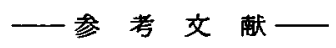

(1) L. N. UsSACHOFF : Proceedings of the Inter. national Conference on the Peaceful Uses of Atomic Energy, 5, 503 (1955).

(2) B. DAvison: "Neutron Transport Theory", (1957), Oxford Univ, Press. 